\title{
PARIS COMO GEOSSÍMBOLO E TRAUMASCAPE: DISCUSSÃO A PROPÓSITO DOS ATENTADOS TERRORISTAS OCORRIDOS EM NOVEMBRO DE 2015
}

\author{
PARIS AS A GEOSYMBOL AND A TRAUMASCAPE: DISCUSSION \\ FOLLOWING THE TERRORIST ATTACKS OCCURRED IN NOVEMBER 2015
}

\author{
PARIS COMME UN GÉOSYMBOLE ET UNE TRAUMASCAPE: DISCUSSION À \\ PROPOS DESATTENTATS TERRORISTES SURVENUS DANS NOVEMBRE 2015 \\ João Luís Jesus Fernandes - Departamento de Geografia e Turismo - \\ Faculdade de Letras da Universidade de Coimbra - Portugal \\ jfernandes@fl.uc.pt
}

\section{Resumo}

Os ataques terroristas que ocorreram em Paris, em novembro de 2015, inserem-se numa estratégia de agressão a lugares com relevância global. Para além dos danos diretos, esses ataques tiram partido da rápida difusão das imagens, com efeitos que ultrapassam os espaços atingidos, criando um ambiente transnacional de medo e insegurança. Nesse sentido, Paris é um alvo vulnerável - porque representa os valores que o terrorismo quer agora atingir, mas também porque se trata de uma cidade com projeção internacional, como simbolicamente se demonstra pela forma como o seu principal ícone - a Torre Eiffel, é encenado e deslocalizado em diferentes lugares do mundo. Pela condenação geral do terrorismo, mas também pela filiação a essa cidade global, os ataques geraram uma rede extensa e alargada de solidariedade.

Palavras-chave: cidade, terrorismo, ícone, geossímbolo.

\begin{abstract}
The terrorist attacks occurred in Paris in November 2015 belong to an aggressive strategy that focuses on places presenting high levels of global relevance. In addition to the direct harm, such attacks take advantage of the rapid diffusion of images, leading to consequences that went beyond the affected places, creating a transnational environment of fear and insecurity. In this sense, Paris is a vulnerable target. This is true because Paris is a symbol that identifies values that terrorism wants now to wipe out, but also because the French capital is a famous city of international renown, as evidenced by the fact that its main icon- the Eiffel Tower, is simulated and relocated in different places around the world. Following an overall denunciation of terrorism, but also as a consequence of a wide world filiation to this city, those attacks generated an extensive wave of global solidarity. Key-words: city, terrorism, icon, geosymbol.
\end{abstract}

\section{Résumé}

Les attentats terroristes qui ont eu lieu à Paris en novembre 2015 sont intégrés dans une stratégie agressive visant les lieux avec pertinence globale. À ajouter aux préjudice directs, ces attaques prennent avantage de la diffusion rapide des images avec des effets au-delà desespaces géographiques touchés, créant un environnement transnational de peur et d'insécurité. En conséquence, Paris est une cité vulnérable - parce qu'elle est l'une des symboles des valeurs que le terrorisme veut maintenant attaquer, mais aussi parce qu'elle est une ville de renommée internationale, comme le montre la façon dont une de leurs icônes - la Tour Eiffel, est simulée et située dans différentes espaces du monde. Par la condamnation générale du terrorisme, mais aussi par l'affiliation à cette ville mondiale, ces attaques ont généré une large solidarité globale.

Mots-clés: ville, terrorisme, icône, geosymbole. 
A centralidade geossimbólica dos lugares no âmbito de um (potencial e/ou efetivo) ataque terrorista

Num cartum do autor Le Kroll publicado no jornal belga Le Soir (e republicado na edição portuguesa $\mathrm{n}^{0} 238$, de dezembro de 2013, da revista Courrier Internacional), o líder de um grupo terrorista escreve num quadro branco uma lista de lugares, potenciais alvos de ataques: Turquia, Sinai, Beirute, Paris. No meio de um grupo de seguidores, armados, armadilhados e preparados para o próximo atentado, enquanto alguém grita que se deve escolher Paris, pois sempre desejou visitar a cidade, um outro terrorista responde que essa deve ser deixada para si, pois vive lá.

Sobre a localização desses ataques, Horácio Capel (2002, p.13, grifo nosso), afirmava que "Los atentados del 11 de septiembre hicieron emerger súbitamente ante la opinión pública norteamericana y mundial algo que estaba ya latente desde algunos años atrás, la capacidad destructora del terrorismo y su potencial para actuar en cualquier lugar del mundo"1. Com esta perspetiva, Capel dava conta do caráter global de uma ameaça que conhece poucas fronteiras, o que não significa, acrescentamos, que a geografia do terrorismo não responda a determinadas lógicas espaciais, quer na localização dos alvos a atingir quer também, como se pode ler em Rogério Haesbaert (2002), no modo complexo como se estrutura a multiterritorialidade dessas organizações.

O terrorismo deve ser compreendido no contexto geral da sociedade de risco que agora se vive e do grau de imprevisibilidade que acompanha as vidas coletivas contemporâneas (Beck, 1998; Amoore e Goede, 2008). Fatores como as dinâmicas de globalização e interdependência; o fim de equilíbrios estruturais que garantiam algumas certezas (como a Guerra Fria); o aumento das mobilidades espaciais concretizadas, ou tentadas, em diferentes escalas geográficas; as oscilações económicas e financeiras constantes num mundo de trocas com forte interdependência planetária; o aumento das desigualdades socioeconómicas ou a erosão do papel controlador e disciplinador de alguns agentes tradicionais, como os Estados, são tendências que convergiram para um sistema complexo e variável marcado pela desregulação dos processos e das dinâmicas territoriais.

A recente vaga de terrorismo deve ser enquadrada na intricada distribuição difusa do poder económico e político, caraterizado por um desordenamento de difícil representação cartográfica, até porque, como 
defende Rogério Haesbaert (2002), se está perante à ação de atores multiterritoriais que, na sua fluidez e plasticidade, articulam diferentes estratégias de organização e expressão espacial. Para o autor, é a complexa articulação entre diferentes categorias de território - zona, redes e aglomerados de exclusão, que confere poder a organizações terroristas que escapam aos mais tradicionais mecanismos de controlo, disciplina e regulação. É esta realidade, caraterizada por Zygmunt Bauman como líquida (2000), que abre porosidades e espaços de afirmação de atores informais que vão contestando poderes e afirmando mensagens de conteúdo político.

Para além da violência, essas associações criminosas veiculam mensagens que, de modo mais ou menos abusivo, são envolvidas por filiações de natureza cultural e religiosa que parecem confirmar os mais negativos vaticínios de autores como Samuel L. Huntington (1999), que submeteram a política às diferenças culturais e a um choque de civilizações que seria o motor do desordenamento desta geometria global contemporânea.

O universo dos grupos terroristas é diversificado e a sua atuação nem sempre obedece a uma estratégia pré-definida. Contudo, pelas densidades que implicam e pela maior visibilidade dos atos, as cidades, sobretudo as denominadas cidades globais (Sassen, 1996), estão entre os alvos mais suscetíveis de atingir num ataque terrorista. O facto confirmou-se, por exemplo, com os atentados de 11 de setembro de 2001, em Nova Iorque.

Como refere Boaz Ganor (2014), a definição de terrorismo não é fácil nem unânime. No entanto, é consensual a ideia que os atos terroristas perseguem diferentes objetivos, como a contestação de poderes preestabelecidos ou a imposição agressiva de ideologias, sistemas de valores e lógicas alternativas. Para atingir esses fins, as ações violentas são preparadas tendo em consideração questões como a dimensão e a propagação dos efeitos trágicos, assim como o simbolismo e a visibilidade dos ataques.

A comunicação acelerada e a rápida difusão das imagens de violência constitui outra das armas de afirmação desses grupos. Numa decisão geográfica coerente, a localização dos ataques não é uma opção inconsequente. Pelo contrário, sabe-se que a propagação de efeitos será tanto maior quanto mais conhecido e celebrizado for o lugar agredido, em especial quando este identifica e se filia nos valores que se pretendem atingir (Quero, 2015).

Nesse sentido, apesar dos sistemas de autodefesa e das práticas de contraterrorismo, Nova Iorque, Madrid, Londres e Paris, cidades onde 
ocorreram ataques terroristas nas duas últimas décadas, fazem parte das escolhas previsíveis por parte de grupos terroristas, facto que faz aumentar a vulnerabilidade dessas metrópoles associadas a um poder e a uma área civilizacional muito visada no terrorismo contemporâneo.

De certo modo, esses lugares terão caraterísticas que os aproximam daquilo que Joël Bonemmaison (1981) denominou por geossímbolos. Pelo menos para quem as perceciona desde o exterior, cidades como Nova Iorque ou Paris representam um estilo de vida, materializam uma cultura e um poder económico e político que se pretende arruinar.

Atingir um destes lugares tem como significado afetar e deixar um rasto de violência e uma traumascape (Turmarkin, 2005) com efeitos que se amplificam e difundem pelo mundo. Investir sobre lugares com densidade geossimbólica faz aumentar a ressonância do acontecimento, expandir o medo e elevar o poder dos autores daquele ato violento.

Os ataques de novembro de 2015 em Paris, seguiram-se a outros, com iguais caraterísticas, ocorridos em cidades como Bagdade e Beirute, mas também em diferentes lugares da Síria, do Iraque ou do Afeganistão (Cardoso, 2015).

A rápida difusão das imagens não ocorre quando o ataque terrorista tem lugar numa outra geografia, fora das metrópoles consideradas como centrais, longe dessa esfera de territórios familiares e de proximidade social, económica, política e cultural. Consoante a localização da tragédia, os mesmos estragos não merecem o mesmo tratamento imediato e igual espaço na impresa, na televisão ou nas redes sociais, numa desigualdade que tem efeitos na perceção e na sensibilização perante a própria violência. Essa assimetria estende-se às reações de natureza política, mais acutilantes nuns casos, mais discretas noutros (Dobkin, 1992; Lewis, 2005; Cole, 2006; Quero, 2015; Alt, 2015).

Paris, como cidade-icónica, enquanto lugar no qual se amplificam as ocorrências trágicas e extraordinárias, seria matéria para uma longa exposição talvez impossível de sistematizar. No entanto, essa relevância pode ver-se por pequenas manifestações, também estas simbólicas, demonstrativas das filiações densas que ligam o mundo a esta cidade. Sob o ponto de vista político, o poder de um ícone terá pouca relevância direta. No entanto, a transnacionalização de uma landmark como a Torre Eiffel não deixa de ser reveladora do caráter global deste espaço urbano. 
Paris, um geossímbolo icónico de projeção global

Em novembro de 2015 (como em janeiro do mesmo ano), Paris foi alvo de ataques terroristas com ampla divulgação nos media e relevantes impactos no crescente sentimento de medo e insegurança, que aumentou em especial nas sociedades europeias e norte-americanas.

Em ambos os casos - o ataque à sede do jornal Charlie Hebdo (em janeiro) e os atentados múltiplos de dezembro, a violência suscitou uma alargada onda de solidariedade internacional, ficando a ideia que a agressão à capital francesa se havia tornado um ato coletivo de violência sobre todas as sociedades livres e democráticas.

Essa cadeia de associação deveu-se à própria natureza das ações terroristas, mas esteve também associada ao sentimento coletivo de pertença e filiação a uma cidade que será mais que um centro urbano do território francês. Essa densidade simbólica da capital francesa terá também ampliado as ações dos grupos terroristas.

Seguindo os critérios de Avraham e Ketter (2008), Paris é uma cidade caraterizada por uma forte imagem; um lugar ao qual não se é indiferente; um território com presença alargada em conteúdos de indústrias criativas, da televisão ao cinema, no qual tudo o que ali ocorre tem um impacto e uma ressonância alargados.

Para se entender essa centralidade, é necessário refletir sobre as caraterísticas centrífugas e centrípetas desta metrópole, mas também sobre o modo como a atual globalização veicula uma perspetiva ainda focada numa narrativa, e numa atratividade, eurocêntrica e ocidental.

Para Baudrillard (1989), a capital francesa está marcada pelo sonho burguês novecentista. Esta é a Cidade das Luzes, do romance e da moda, território do glamour, do charme e da Belle Époque, cidade de correntes artísticas relevantes devedoras, sobretudo do esplendor cultural que França viveu no século XIX e na primeira metade do século XX.

Sem que seja possível resumir o seu percurso urbano, Paris é ponto de chegada de importantes fluxos turísticos; território de acontecimentos fundadores das sociedades modernas como a Revolução Francesa ou o Maio de 68. É também um espaço topobiográfico, lugar (de chegada e partida) de políticos e artistas, de pintores, escritores ou cineastas, de desenhadores de moda. Paris é Picasso e Hemingway, Sartre e Edith Piaf, Victor Hugo e Modigliani, cidade de chegada de criativos, de exílios vários, de trocas e misturas criativas. Centro de difusão de múltiplas correntes estéticas, Paris 
aproximar-se-á, com altos e baixos ao longo da sua história recente, da ideia de lugar cosmopolita descrito por autores como Richard Florida (2008).

Apenas estudos mais apurados ponderarão o caráter estereotipado e positivo da imagem global desta cidade, à qual se devem acrescentar propriedades menos atrativas (e menos conhecidas) como, por exemplo,as periferias suburbanas de minorias étnicas pouco integradas.

Apesar de tudo, para a opinião pública mundial, os atentados de 2015 afetaram uma cidade icónica, um território urbano que, mesmo que nunca se tenha visitado, vai exportando ícones de uma pop culture massificada nos quais se incluem referências como Campos Elíseos, Montmartre, Louvre, Sena, Notre-Dame, Arco do Triunfo, Moulin Rouge ou Sacré Coeur. Mesmo que, para muitos, essas designações pouco mais sejam que denominações imprecisas de difícil identificação espacial, essa cidade de restaurantes e cafés simbólicos (como o Deux Magots) vai-se inscrevendo no imaginário coletivo e ganhando intensidade simbólica, parecendo, por isso, representar uma certa ideia de globalização que encurta as distâncias e aproxima os lugares e as pessoas.

Segundo Lynch (1999), um dos elementos que mais condicionam e fixam a perceção de uma cidade são estas landmarks que deixam rasto, que criam uma referência de identidade geográfica, ainda que, considerando aqui apenas os ícones de expressão material, estas não passem, quase sempre, de um edifício, de uma praça, uma igreja ou uma torre.

De todos os fatores que identificam Paris, a Torre Eiffel será,segundo Freytag (2010), um dos mais emblemáticos iconic landmark, um ícone que sobressai na paisagem e no skyline deste espaço urbano (figura 1).

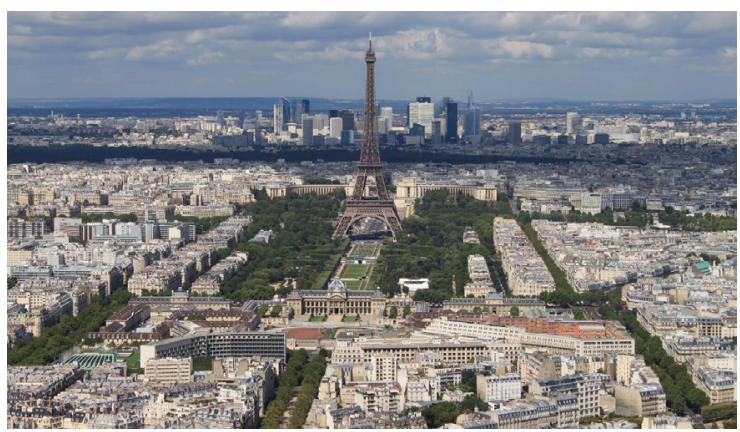

Figura 1 - A Torre Eiffel na paisagem parisiense (perspetiva desde o Edifício/Torre Montparnasse). 
Nascido no contexto de uma exposição internacional (a Exposition Universelle de Paris, de 1889) e de um período de exaltação industrial do país, esta construção tem origem num evento que pretendeu reforçar e exportar a imagem da capital francesa. Depois de algumas hesitações sobre a sua utilidade, a patrimonialização da Torre Eiffel agregou Paris a um ícone que se foi afirmando como um dos principais marcadores globais da cidade.

Segundo Crandall, Backstrom, Huttenlocher e Kleinberg (2009), Paris era, à época do estudo realizado por esses autores (e segundo a base de imagens da plataforma digital flickr), a quarta cidade do mundo mais fotografada, numa lista na qual se incluem centros globais como Nova Iorque ( $1^{\circ}$ lugar), Londres $\left(2^{\circ}\right)$, São Francisco $\left(3^{\circ}\right)$ ou Los Angeles $\left(5^{\circ}\right)$.

Ainda de acordo com estes autores, a Torre Eiffel, logo seguida pela Catedral de Notre-Dame e pelo Museu do Louvre, é a landmarke a referência mais registada pelos fotógrafos na cidade.

Para além de amadores que representam o território nas suas máquinas digitais, Paris é uma cidade de fotógrafos emblemáticos, como Robert Doisneau. A difusão intertextual das fotografias a preto e branco de Doisneau muito contribuiu para uma certa glorificação desta cidade e dos modos de vida associados a este espaço urbano (Gautrand, 2014).

Contudo, Paris é o lugar que atrai, como sempre atraiu estudantes e intelectuais, pintores, escritores e boémios, mas é também a cidade que se exporta, que serviu de referência enquanto símbolo de modernidade.

Não se tentará aqui nenhum exercício de comparação temporal nem importa se no passado terão ocorrido tendências semelhantes. No entanto, esta hipermodernidade (Lipovetsky, 2011) é uma época de encenações que fazem paisagem, de réplicas que associam lugares distantes e os tornam aparentados a referências espaciais icónicas com as quais qualquer associação será positiva. Neste ponto de vista, a Europa e, em particular, Paris, continua a ser uma referência (Fernandes, 2014).

Não é possível quantificar a exportação da Torre Eiffel que, desde a capital de França, se difunde para o mundo em forma de imagens cinematográficas, fotografias e pinturas, de torres miniaturizadas, estampadas em camisolas e gravadas em peças de plástico, cerâmica ou vidro. Ao mesmo tempo que talvez o banalize, toda esta cultura popular turistificada reforça o ícone, faz Paris circular pelo mundo em formato souvenir, impõe-se porque alguém quer demonstrar que ali esteve, que ali passou férias 
ou viveu a lua-de-mel, que ali trabalhou ou por lá parou num qualquer percurso turístico ou profissional.

A exportação (e deslocalização) da Torre Eiffel faz-se ainda pela réplica que se constrói e se fixa ao solo num qualquer lugar. Símbolo da modernidade e da industrialização, da era do ferro e da engenharia, a Torre Eiffel foi apropriada pela (hiper) pós-modernidade e pela globalização. Assim se encenou, multiplicou, deslocalizou e miniaturizou, assim também se inovou em tamanhos, texturas, enquadramentos paisagísticos e adereços.

Deslocalizando um dos mais icónicos símbolos urbanos do mundo, é possível identificar uma extensa geografia de réplicas desta torre parisiense (cerca de meia centena) que, na Europa, mas também fora desta, nos leva a lugares que vão de Portugal à República Checa, do Paquistão ao Cazaquistão, da Î́ndia à África do Sul e ao Brasil (figura 2).

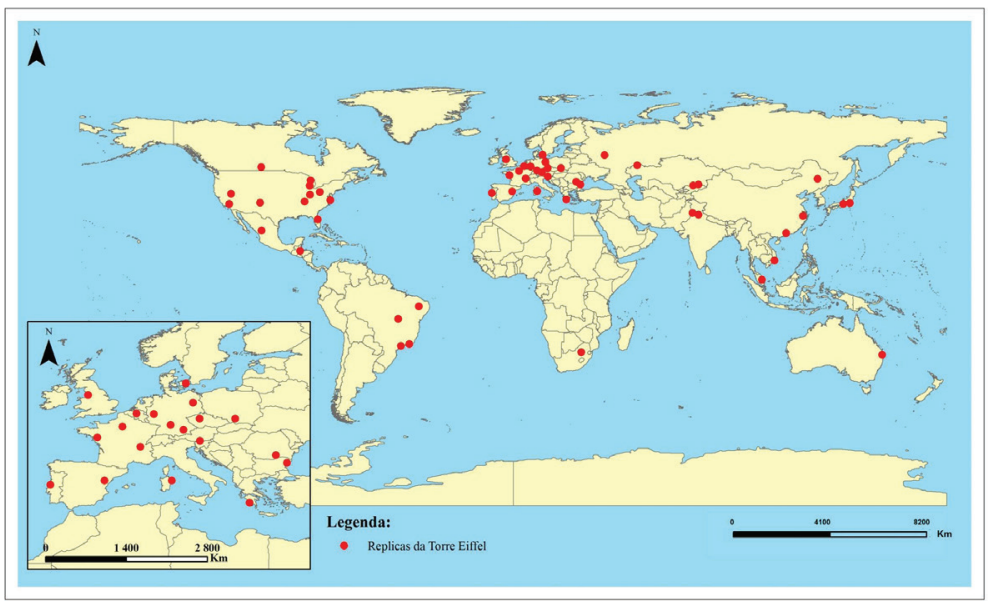

Fig. 2 - Distribuição mundial das 52 réplicas da Torre Eiffel, contabilizadas em Maio de 2013 (Fonte: Fernandes, 2014).

Uma das mais populares e carismáticas torres falsas encontra-se nos EUA. Ainda segundo Crandall, Backstrom, Huttenlocher e Kleinberg (2009), Las Vegas é a $15^{\mathrm{a}}$ cidade mais representada nas fotografias publicadas na plataforma flickr. Nesta aglomeração de casinos e encenações, o ícone mais fotografado é a falsa Torre Eiffel localizada no Hotel-Casino 
Paris Las Vegas, propriedade da empresa Caesars Entertainment Corp. Empreendimento evocativo da capital francesa, o edifício central incorpora elementos arquitetónicos do Louvre e da Ópera de Paris. Ali construíram-se também outras evocações dessa cidade, como um Arco do Triunfo (a uma escala de 2/3) ou uma Fontaine des Mers semelhante à existente na Praça da Concórdia (figura 3).

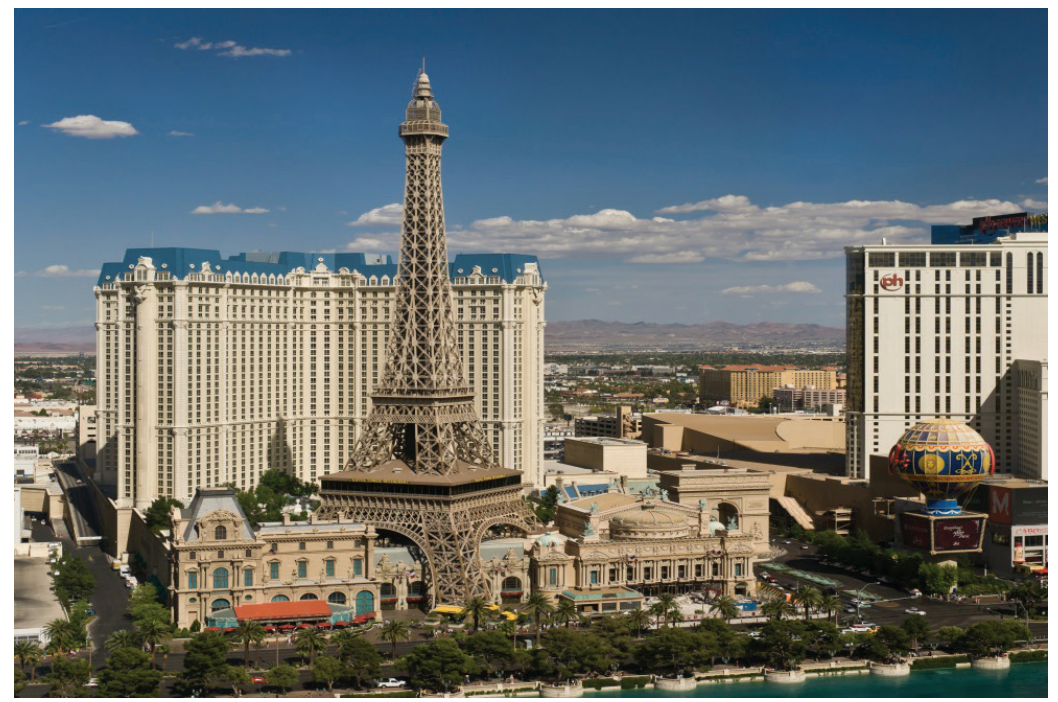

Fig. 3- Hotel-Casino Paris Las Vegas, construído em 1999, onde se destaca uma réplica da Torre Eiffel, à escala 1/2 (Fotografia de Jürgen Matern, in http://www.juergen-matern.de/).

Iniciativas privadas, algumas, obras públicas outras, a autoria destas torres é diversificada, como também é variável a escala, são variáveis os materiais e diversas as funcionalidades e os objetivos dessas construções: estéticos na maior parte das vezes, para distribuição de sinais de comunicação, noutras; ou para promoção e venda de produtos que, de algum modo, se associam a esta cidade de moda e sofisticação.

Nalguns casos, reconstrói-se uma torre Eiffel porque se pretende registar, e exteriorizar, alguma filiação à cidade. Assim ocorre com antigos emigrantes na França que, no regresso aos lugares de origem, ali exibem esta marca. Assim acontece também com as memórias evocativas de trajetórias de e/imigração, como ocorreu com a réplica construída no concelho de Leiria, em Portugal (figura 4). 


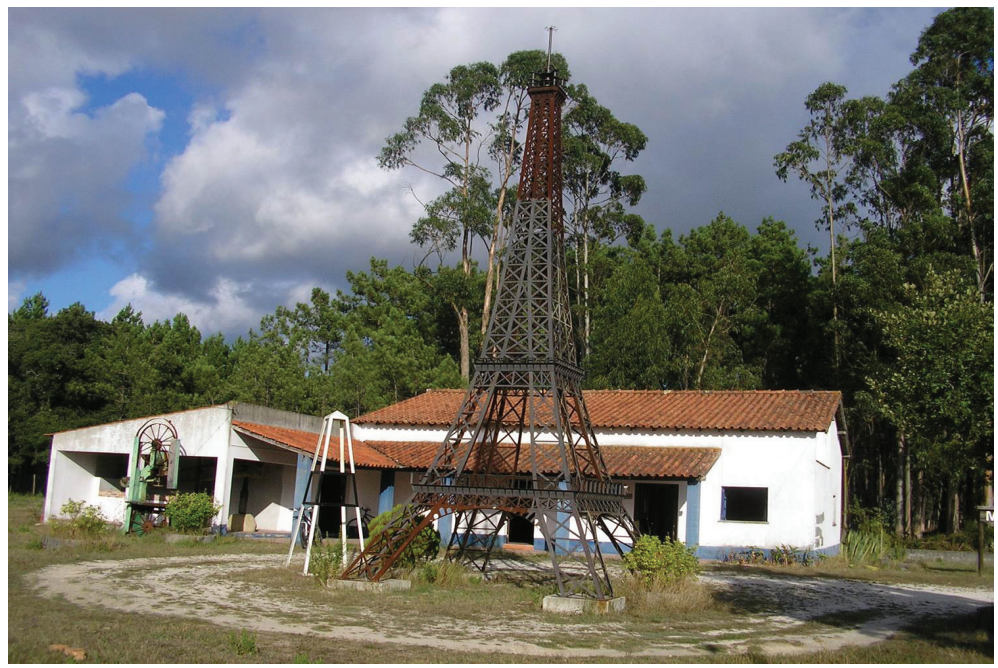

Fig. 4- Torre Eiffel encenada em Monte Redondo, concelho de Leiria (Portugal).

Em 2007, em Monte Redondo, pequena localidade do concelho de Leiria, uma instituição local dedicou as festas da vila à temática das migrações. As festividades evocaram trajetórias de saídas e entradas migratórias e encenaram monumentos como um obelisco de Kiev (na época era elevada a imigração ucraniana na região), mas também a Porta de Brandenburgo (Berlim), a Ponte do Luxemburgo, um moinho da Holanda e, entre outras, a Torre Eiffel. Após a festa, todas as outras encenações (construídas com materiais perecíveis), foram destruídas, mas a torre parisiense (de ferro e aço) permaneceu, deslocada para as proximidades de um museu etnológico, igualmente evocativo das dinâmicas migratórias. Tal como a original, também esta réplica da Torre Eiffel resultou de uma exposição e de uma celebração².

Nesta transmutação geográfica, a Torre Eiffel foi arrancada do sítio original, o Champ de Mars parisiense, e emerge agora noutros contextos, junto a lojas, em parques temáticos, no topo de telhados fabris, nalgum espaço verde. Nestas paisagens transgénicas (Domingues, 2012), encontram-se representações híbridas, mistura de símbolos, como aquela que acrescenta um chapéu texano à réplica da torre localizada naquele estado norte-americano, numa cidade também denominada Paris, celebrizada por um filme de Wim Wender, de 1984 (Paris, Texas) (figura 5). 


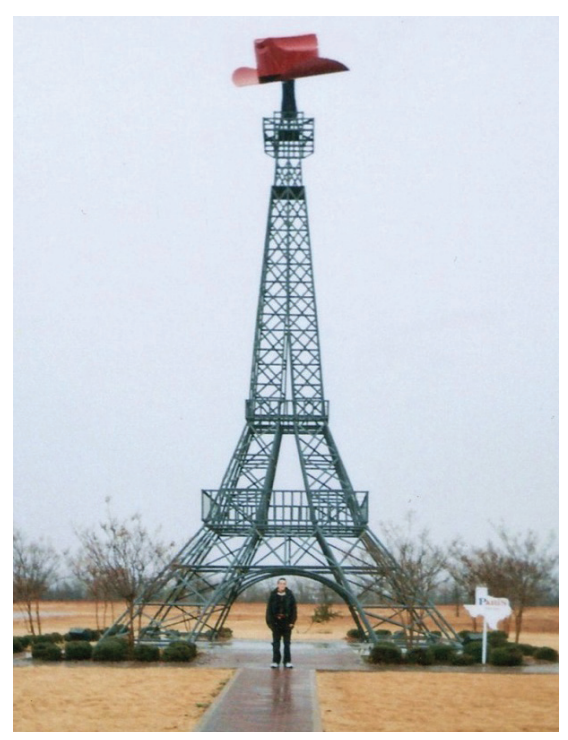

Fig. 5 - Réplica da Torre Eiffel, em Paris (Texas, EUA) (Fotografia de Jeanne Boleyn).

Também na América do Sul, associada à Europa por fluxos migratórios nos dois sentidos, se fixaram símbolos evocativos da paisagem e da identidade francesa e europeia. Em pleno sertão cearense, no nordeste brasileiro, perto de Santana do Cariri, foi construído um parque temático denominado Euroville. Iniciativa individual de um antigo emigrante na Europa, lá se localiza e reconstrói a casa francesa, a grega ou a portuguesa, lá se encena também a Torre Eiffel, numa paisagem de exposição que copia, encena e comprime realidades exógenas.

Ainda no Brasil, na paisagem urbana de Belém do Pará, a certificação simbólica do progresso resultante do período áureo do ciclo da borracha, do século XIX, fez-se invocando a Europa. Nessa cidade, este esplendor também se promoveu pela filiação a Paris, às suas referências e ao seu desenho urbanístico. Na morfologia urbana de Belém do Pará, inscreve-se o projeto do boulevard que, a partir da capital francesa de Haussmann, deixou marcas em muitos espaços urbanos europeus e não europeus. Mais que um projeto de cidade que serviu de exemplo a outros lugares, Paris era o símbolo da modernidade e do progresso, do comércio de bom gosto e sofisticação inspirado em espaços emblemáticos como as Galeries Lafayette (figura 6). 

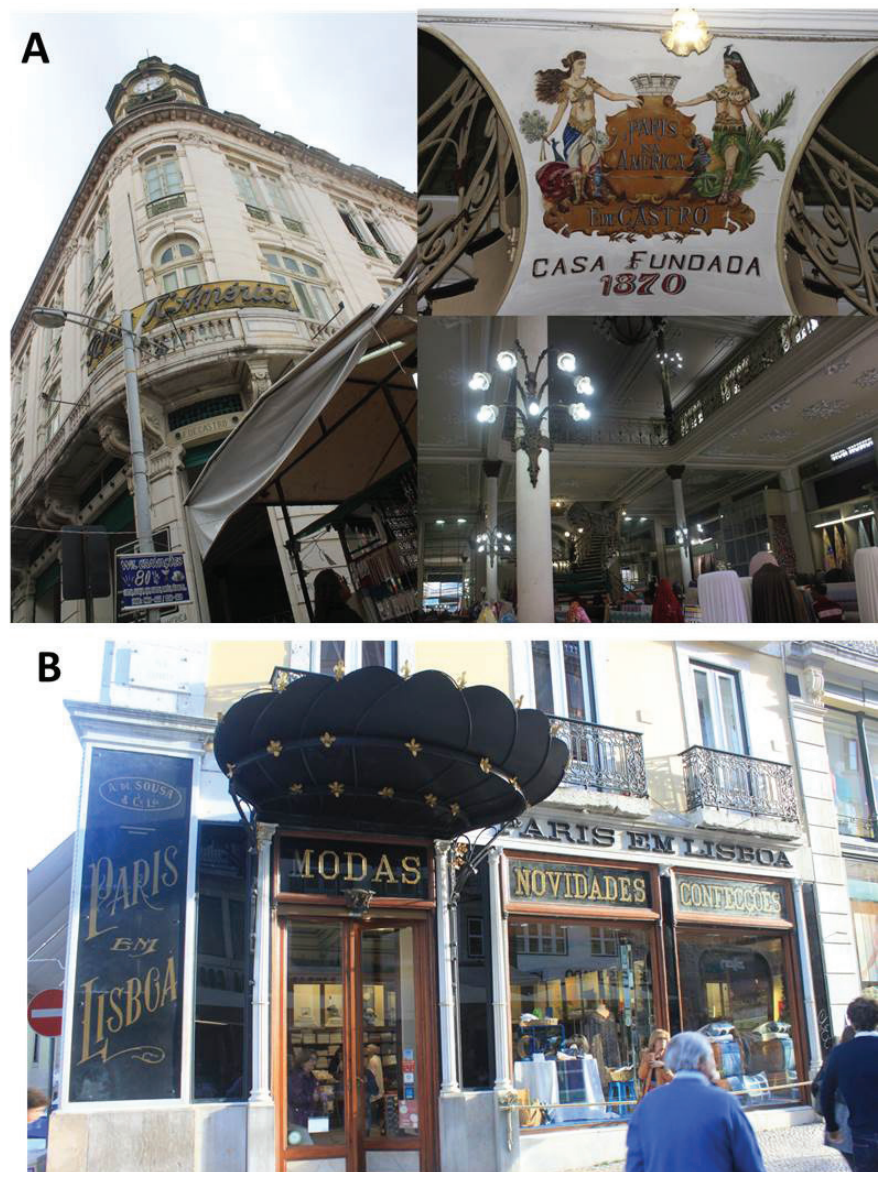

Fig. 6 - Um espaço comercial evocativo de Paris, em Belém do Pará (a casa Paris n'América) (A), e um outro, na mesma linha, em Lisboa (B) (o estabelecimento Paris em Lisboa): a difusão espacial da Belle Époque, a partir da capital francesa.

Essa associação de Paris a um estilo de vida continua na contemporaneidade, facto que estimula os fluxos turísticos e atravessa linguagens, incorporando-se no mundo digital da publicidade e do marketing. Para a venda de produtos, filma-se e fotografa-se a cidade. Paris é o cenário que promove a comercialização de produtos de luxo, promove perfumes caros e outros artigos vocacionados para consumo por parte das elites, sobretudo nos domínios da alta costura e da moda. 
São essas as caraterísticas que atraem a atenção e o interesse. De quem quer participar do esplendor consumista e simbólico de uma certa globalização, mas também dos poderes informais e subterrâneos que pretendem perturbar o sistema e publicitar os seus atos de violência.

\section{0 terrorismo e a produção de uma traumascape urbana}

Os ataques de novembro de 2015, como já tinha ocorrido com os atentados nesta cidade de Paris em janeiro do mesmo ano, deixaram consequências que se arrastaram no tempo. Pelos seus efeitos diretos e indiretos, de curto e de longo prazo, esses atos violentos serão sempre um desafio à capacidade de resiliência de um espaço urbano (Coaffee, 2009).

Pela sua inserção nesta cartografia do terrorismo, Paris é cidade de uma traumascape cujos efeitos imediatos (logo após as ocorrências) se traduziram no aumento das regras de segurança e controlo, na ampliação dos poderes das forças policiais, na criação de um regime de exceção que foi aprovado estender-se até fevereiro de 2017. Nas horas imediatas após os atentados de 13 de novembro, o bairro de St. Denis foi alvo de uma incursão policial, os espaços públicos e privados da cidade foram vividos a um outro ritmo e o quotidiano foi interrompido por uma outra lógica espácio-temporal. Nesta estratégia de contraterrorismo, alguns eventos foram cancelados e espaços, como o parque de diversões Disneyland Paris, foram encerrados. A concentração de multidões foi evitada, as manifestações proibidas, os movimentos regulados e vigiados, o número de elementos de segurança alargado - junto a instituições como a Assembleia Nacional, mas também perto de ícones como a Torre Eiffel.

Os locais dos atentados tornaram-se centros de convergência e microterritórios de atenção redobrada, com a concentração de polícias, especialistas de investigação e jornalistas, mas também de anónimos que prestam homenagem às vítimas.

Nessa traumascape parisiense multiplicaram-se os santuários espontâneos, junto aos lugares onde ocorreram os assassinatos. Depositam-se flores e inscrições, reza-se e chora-se. As multidões que se evitam nos espetáculos cancelados, são aqui repostas nos espaços e tempos de homenagem, mas também de obstinação silenciosa.

Como sinal de união e resistência coletivas, nesta cityscape política e sentimental, mostram-se agora as cores de França, ouve-se La 
Marseillaise e desfraldam-se as bandeiras tricolores em monumentos e instituições públicas, mas também em janelas de habitações familiares.

Como resultado combinado de uma reação ampla e global ao terrorismo, mas também como demonstração de uma elevada filiação transnacional à capital francesa, as manifestações de pesar ultrapassaram fronteiras. A 17 de novembro, num jogo de futebol, em Londres, 80 mil espetadores cantaram o hino francês. Nos dias seguintes, uma rede social (o Facebook) - um novo espaço geográfico de afirmação, associou as cores da bandeira francesa ao perfil dos utilizadores. Um pouco por todo o mundo, usou-se a luz enquanto mensagem política e iluminaram-se monumentos e edifícios com as cores azul, branca e vermelha: do London Eye à sede do governo albanês, em Tirana; da Porta de Brandenburgo, em Berlim, ao edifício Taipéi 101, em Taiwan; da sede do governo mexicano ao Cristo Redentor (no Rio de Janeiro) e à Ópera de Sydney, na Austrália.

A Torre Eiffel encenada em Las Vegas foi também espaço de homenagem, resistência e renovada filiação à cidade que inspirou aquele território de jogo e entretenimento. Em Nova Iorque, o novo The One World Trade Center juntou-se a esta manifestação global contra o terrorismo neste ponto, as duas cidades criaram um laço simbólico, uma ponte que se estende entre o 9 de setembro de 2001 e o 13 de novembro de 2015.

A cidade não é um mero espaço económico. É lugar de lazer e turismo, mas é também um território político e de resistência. Uma das estratégias de Paris para a captação de fluxos turísticos assenta nos slogans; Cosmopolitan Paris; Creative Paris e Friendly Paris (Freytag, 2010). No entanto, a cidade está marcada por ritmos que podem ser perturbados por acontecimentos excecionais. A vida urbana é sensível às conjunturas e aos contextos.

O aumento do risco nesses espaços urbanos advém da associação das cidades a determinados valores, mas resulta também do poder de difusão de acontecimentos de espaços que servem de referência global. Como se notou pela simbólica difusão espacial das encenações da Torre Eiffel, Paris é uma referência. Tudo isto é herança de um mundo eurocentrado, de uma cultura global polarizada por modelos ocidentais. Mas é também com essa assimetria que os grupos terroristas contam. Com os ataques a Paris e com todas as consequências imediatas daí resultantes, interrompem-se a velocidade e a continuidade que, para David Harvey (2011), são condições essenciais do capitalismo. Ao mesmo tempo, alcança-se uma visibilidade que é ampliada pelo caráter transnacional de uma cidade exportadora de símbolos e ícones. 


\section{Notas}

1 “Os atentados de 11 de setembro fizeram emergir rapidamente na opinião pública norte-americana e mundial algo que estava latente já há alguns anos, a capacidade destruidora do terrorismo e seu potencial para atuar em qualquer lugar do mundo." (Tradução nossa).

2 Informações gentilmente cedidas pelo Sr. João Moital, um dos responsáveis pelas celebrações que levaram à construção dessa réplica da Torre Eiffel, no concelho de Leiria (Portugal).

\section{Referências}

Alt, V. Como os mortos em Paris ofuscaram as vítimas do BokoHaram. Politike. Política Internacional, Direito Humanos, Economia. Disponível em: < http:/ politike.cartacapital.com.br/nigeria-x-franca-quanto-vale-a-vida-de-um-serhumano/>. Acesso em: 28 nov. 2015.

Amoore, L. ; Goede, M. Risk and the war on terror. London: Routledge, 2008.

Avraham, E. ;Ketter, E. Media strategies for marketing places in crisis. Amsterdam: Butterworth-Heinemann/Elsevier, 2008.

Baudrillard, J. América. Lisboa: João Azevedo Editor, 1989.

Bauman, Z. Liquid modernity. Cambridge: Polity Press, 2000.

Beck, U. World risk society. Cambridge: polity press, 1998.

Bonnemaison, J. Voyage autor du territoire. L'Espace Géographique, n. 4, p. 249262, 1981.

CAPEL, H. La geografía después de los atentados del 11 de septiembre. Terra Livre, Ano 18, vol. I, n. 18, p. 11-36, 2002.

Cardoso, R. (2015). Um novo espetro ameaça a Europa. Courrier Internacional, n. 238 , p. 3.

Coaffee, J. Terrorism, risk and the global city. Towards urban resilience. Farnham: Ashgate, 2009.

Cole, B. (Ed.).Conflict, terrorism and the media in Asia. London: Routledge, 2006.

Crandall, D.; Backstrom, L.;Huttenlocher, D.; Kleinberg, J. Mapping the world's photos.International World Wide Web Conference Committee, April 20-24, 2009.

Dobkin, B. A. Tales of terror: Television news and the construction of the terrorist threat. New York: Praeger, 1992.

Domingues, Á. Vida no campo. Porto: Dafne Editora, 2012. 
FERNANDES, J. As paisagens culturais europeias como referências icónicas - paisagens de encenação da Europa fora do continente europeu. In: Pina, H., Remoaldo, P., Ramos, M.\&Marques, H. (Ed.). The overarching issues of the european space: the territorial diversity of opportunities in a scenario of crisis. Bucarest:Milena Press, 2014. p. 51-71.

Florida, R. Who's your city? New York: Basic Books, 2008.

Freytag, T. Déjà-vu: tourist practices of repeat visitors in the city of Paris. Social Geography, n. 5, p.49-58, 2010.

GANOR, B. Defining terrorism. Is one man's terrorist another man's freedom fighter? In: Lowe, D.; Turk, A.; Das, D. K. (Ed.).Examining political violence. Studies of terrorism, counterterrorism, and internal war. Boca Raton: CRC Press, 2014. p.3-24.

Gautrand, J. C. Robert Doisneau. Berlin: Taschen, 2014.

Haesbaert, R. A multiterritorialidade do mundo e o exemplo da Al Qaeda. Terra Livre, Ano 18, v. I, n. 18, p. 37- 46, 2002.

Harvey, D. O Enigma do capital e as crises do capitalismo. Lisboa: Bizâncio, 2011.

HUNTINGTON, S. P. O choque das civilizações e a mudança na ordem mundial. Lisboa: Gradiva, 1999.

Lewis, J. Language wars: The role of media and culture in global terror and political violence. London: Pluto Press, 2005.

Lipovetsky, G. Os tempos hipermodernos. Lisboa: Edições 70, 2011.

Lynch, K. A imagem da cidade. Lisboa: Edições 70, 1999.

Quero, C. O ataque ao Charlie Hebdo: uma guerra de propaganda.Politike. Política Internacional, Direito Humanos, Economia, 2015. Disponível em: $<$ http://politike.cartacapital.com.br/o-ataque-ao-charlie-hebdo-uma-guerra-depropaganda/>. Acesso em: 28 nov. 2015.

SASSEN, S. La ville globale. Paris: Descartes \& Cie., 1996.

TUMARKIN, M. Traumascapes: The power and fate of places transformed by tragedy.Melbourne: Melbourne University Press, 2005.

João Luís Jesus Fernandes - Possui Licenciatura em Geografia pela Universidade de Coimbra. Possui Mestrado e Doutorado pela mesma Universidade. Atualmente é professor Auxiliar do Departamento de Geografia da Faculdade de Letras de Coimbra.

Recebido para publicação em 02 de novembro 2015 Aceito para publicação em 14 de dezembro de 2015 